\title{
Penanaman Sengon dalam Gerakan Penghijauan di Desa Sukoharjo, Kecamatan Tirtomoyo, Kabupaten Wonogiri
}

\author{
Hery Widijanto* dan Suwarto \\ Program Studi Ilmu Tanah, Fakultas Pertanian, Universitas Sebelas Maret \\ *Corresponding author: herywidijanto@staff.uns.ac.id
}

\begin{abstract}
ABSTRAK
Kegiatan pengabdian ini bertujuan untuk memperkenalkan metode konservasi secara vegetatif untuk usaha menekan erosi dan melestarikan sumberdaya lahan melalui penghijauan dengan tanaman sengon. Kegiatan ini bekerjasama dengan dua mitra yaitu: (1) Kelompok Tani "Ngudi Mulyo", dan (2) Kelompok Tani "Ngudi Tani I" yang berlokasi di Desa Sukoharjo, Tirtomoyo, Wonogiri. Bidang usaha yang dikembangkan oleh dua mitra tersebut adalah pertanian lahan kering. Permasalahan yang dihadapi oleh kedua mitra adalah kondisi lahannya berbukit dan bergelombang serta semakin lama mengalami degradasi karena erosi yang cukup tinggi. Dalam kegiatan pengabdian masyarakat ini akan diperkenalkan pada petani cara vegetatif untuk usaha menekan erosi dan melestarikan sumberdaya lahan melalui penghijauan dengan tanaman sengon. Kegiatan yang dilakukan meliputi: persiapan (koordinasi), pengadaan bibit, pupuk, alat dan sosialisasi tentang metode konservasi tanah secara vegetatif untuk usaha menekan erosi dan melestarikan sumberdaya lahan melalui penghijauan dengan tanaman sengon. Pasca sosialisasi dan pemberian bibit sengon, dilakukan monitoring terkait penanaman dan pemeliharaan. Hasil kegiatan menunjukkan antusias masyarakat dalam mengikuti sosialisasi dan melaksanakan penanaman bibit sengon untuk penghijauan di tanah warga.
\end{abstract}

Kata kunci : konservasi, penghijauan, sengon, pupuk organik

\section{ABSTRACT}

This service activities aimed at introduce the vegetative conservation methods for minimized erosion and conserve land resources by afforestation with sengon. This activity was in collaboration with two partners, namely: (1) "Ngudi Mulyo" and (2) "Ngudi Tani I" Farmers Groups located in Sukoharjo Village, Tirtomoyo, Wonogiri. The business fields developed by the two partners were dry land agriculture. The problem that the land was hilly and rolling and more degradated due to high erosion. In this program, farmers will be introduced with vegetative method to reduced erosion and preserved land resources by reforestation with sengon. Activities included: preparation (coordination), procurement of seeds, fertilizers, tools and socialization on vegetative soil conservation method to reduced erosion and preserve land resources by reforestation with sengon. After the socialization and giving of sengon seeds, monitoring was carried out related to planting and maintenance. The results of the program showed the enthusiasm of the community in participating both in socialization and planting of sengon seeds for reforestation.

Key words : conservation, greening, sengon, organic fertilizer

\section{PENDAHULUAN}

Pengertian konservasi adalah upaya atau tindakan pencegahan atau pengendalian dan pemulihan atau penyelamatan sumberdaya alam yang pengelolaannya berdasarkan prinsip kelestarian. Secara sederhana definisi konservasi tanah merupakan upaya atau tindakan konservasi terhadap lahan yang pengelolaannya berprinsip pada penggunaan atau pemanfaatan lahan yang disesuaikan dengan potensi dan kemampuannya (Karyati and S. Sarminah, 2018). Konservasi tanah dan air mengarah kepada terciptanya sistem pertanian berkelanjutan yang didukung 
oleh teknologi dan kelembagaan serta mampu meningkatkan kesejahteraan masyarakat dan melestarikan sumber daya lahan serta lingkungan (Sutrisno and N. Heryani, 2013). Pada dasarnya teknik konservasi dibedakan menjadi tiga yaitu: (a) vegetatif; (b) mekanik; dan (c) kimia. Teknik konservasi mekanik dan vegetatif telah banyak diteliti dan dikembangkan. Namun mengingat teknik mekanik umumnya mahal, maka teknik vegetatif berpotensi untuk lebih diterima oleh masyarakat (Subagyono et al., 2003).

Kegiatan ini bekerjasama dengan dua mitra, yaitu: (1) Kelompok Tani "Ngudi Mulyo", dan (2) Kelompok Tani "Ngudi Tani I" y ang berlokasi di Desa Sukoharjo, Tirtomoyo, Wonogiri, dengan jarak tempuh sekitar $80 \mathrm{~km}$ dari Fakultas Pertanian UNS. Bidang usaha yang dikembangkan oleh dua mitra tersebut adalah budidaya tanaman buah-buahan lahan kering. Manajemen yang dikembangkan dalam kelompok tani ini berdasarkan kegotongroyongan dan kebersamaan. Permasalahan Mitra (1) dan (2) adalah kondisi lahannya semakin lama mengalami degradasi karena erosi yang cukup tinggi. Teknologi pelestarian sumberdaya lahan harus dikuasai dan dilaksanakan dalam usaha bidang pertanian, karena banyak terjadi kerusakan tanah akibat kekeliruan atau kesalakan dalam pengelolaan tanah serta tanamannya.Tindakan serta perlakuan-perlakuan yang tidak disadari telah menimbulkan kerusakan tanah yang dampaknya harus ditanggung oleh semua masyarakat sekitar.

Erosi merupakan penyebab utama terjadinya kerusakan tanah atau degradasi tanah, sehingga dalam pelestraian sumberdaya lahan pengendalian erosi mutlak harus dilakukan. Pada dasarnya ada tiga proses penyebab erosi yaitu pelepasan (detachment) partikel tanah, pengangkutan (transportation), dan pengendapan (sedimentation) (Subagyono et al., 2003). Dalam pengendalian erosi harus didasarkan pada prinsip-prinsip : (1) memperbesar resistensi permukaan tanah sehingga lapisan permukaan tanah tahan terhadap pengaruh tumbukan butir-butir air hujan; (2) memperbesar kapasitas infiltrasi tanah sehingga aliran permukaan dapat dikurangi; (3) mengurangi laju aliran permukaan agar daya pengikisan terhadap tanah menjadi kecil; (4) memperbesar resistensi tanah sehingga daya rusak dan daya hanyut aliran permukaan terhadap partikel-partikel tanah dapat diperkecil.
Setelah mengetahui prinsip tersebut maka usaha pelestarian sumbedaya lahan dapat dilakukan dengan beberapa teknologi/cara sebagi berikut: (1) cara vegetatif atau biologi; (2) cara mekanik; (3) cara kimiawi yaitu dengan pemanfaatan bahan bahan pembenah tanah; (4) terasering.

\section{METODE}

Dalam pelaksanaan kegiatan pengabdian masyarakat kali ini akan diperkenalkan pada petani cara vegetatif untuk usaha menekan erosi dan melestarikan sumberdaya lahan melalui penghijauan dengan tanaman sengon. Usaha pengendalian erosi dan pelestarian sumberdaya lahan dengan cara vegetatif didasarkan pada peranan tanaman dimana tanaman itu mempunyai peranan untuk mengurangi erosi dan melestarikan sumberdaya lahan. Metode yang digunakan dalam kegiatan ini adalah metode partisipatif masyarakat yang meliputi : sosialisasi, diskusi, praktek penanaman dan pemeliharaan. Partisipasi masyarakat sering diartikan keikutsertaan, keterlibatan dan kesamaan anggota masyarakat dalam suatu kegiatan tertentu baik secara langsung maupun tidak langsung, sejak dari gagasan, perumusan kebijakan, pelaksanaan program dan evaluasi. Partisipasi secara langsung berarti anggota masyarakat tersebut ikut memberikan bantuan tenaga dalam kegiatan yang dilaksanakan (Rubiantoro and Haryanto, 2013)

\section{HASIL DAN PEMBAHASAN}

Kegiatan yang dilakukan meliputi: (1) koordinasi dengan mitra untuk menentukan waktu, tempat melaksanaan serta materi yang dibutuhkan mitra; (2) penyiapan peralatan dan perlengkapan; (3) sodialisasi dan praktek pengendalian erosi dan pelestarian sumberdaya lahan dengan cara vegetatif didasarkan pada peranan tanaman dimana tanaman itu mempunyai peranan untuk mengurangi erosi dan melestarikan sumberdaya lahan dengan penghijauan tanaman sengon; (4) pemeliharaan tanaman sengon secara berkelanjutan sebagai usaha pelestarian sumberdaya lahan

Koordinasi dengan Mitra dilakukan pada tanggal 16 Juni 2019 dan didampingi Ketua Gapoktan Desa Sukoharjo. Koordinasi diawali dengan ketua kelomok tani Mitra 1 (KT Ngudi Mulyo), dusun Bonagung. Bersama ketua kelompok tani (bapak Supriyanto), tim peneliti memperkenalkan diri, kemudian memberikan 
gambaran tentang kegiatan yang akan dilakukan. Selanjutnya dipaparkan tahap-tahap kegiatan yang direncanakan bersama, terkait waktu dan kesiapan warga untuk mengikuti kegiatan yang direncanakan. Koordinasi dilanjutkan ke MItra 2 di dusun Ngembong (KT Ngudi Tani I), juga didiskusikan hal yang sama. Dalam koordinasi yang telah dilakukan, dicapai kesepatan bahwa lokasi penyuluhan dan sosialisasi kegiatan dilakukan di rumah bapak Kamiso (dusun Ngembong) pada tanggal 18 juli 2019

Sosialisasi kegiatan dilakukan pada tanggal 18 Juli 2019 bertempat di Dusun Ngembong, Desa Sukoharjo Jumlah petani yang ikut dalam sosialisasi adalah 50 orang, yang berasal dari $2 \mathrm{KT}$ mitra dan perwakilan dari Gapoktan. Dalam sosisalisasi diberikan metari tentang perlunya melakukan konservasi dan teknik konservasi yang ditawarkan. Beberapa peranan konservasi tanah dan air adalah ; (1) Penyelamatan lahan kritis (2). Menjaga/menjamin kesuburan tanah (3). Pengendalian erosi dan sedimentasi (4). Pengendalian banjir (menjaga keseimbangan tata air) (5). Pengendalian pencemaran air sesuai dengan standar baku mutu lingkungan (Karyati and S. Sarminah, 2018). Penerapan teknik konservasi tanah tidak hanya ditujukan untuk mengendalikan erosi, tetapi juga untuk memperbaiki dan meningkatkan kualitas tanah yang terdegradasi (Sutrisno and N. Heryani, 2013). Teknik konservasi tanah secara vegetatif adalah setiap pemanfaatan tanaman/vegetasi maupun sisa-sisa tanaman sebagai media pelindung tanah dari erosi, penghambat laju aliran permukaan, peningkatan kandungan lengas tanah, serta perbaikan sifat-sifat tanah, baik sifat fisik, kimia maupun biologi (Sukasah et al., 2018). Di akhir sosialisasi diberikan bibit sengon untuk penghijauan. Bibit sengon yang diberikan kepada petani sejumlah 1.500 bibit sengon, beserta alat penunjangnya (cangkul, sabit, sekop dan terpal).

Penanaman dilakukan dengan diawali pembersihan gulma disekitar lokasis, kemudian dibuat lubang tanam tepat dengan ukuran sekitar $30 \mathrm{~cm} \times 30 \mathrm{~cm} \times 30 \mathrm{~cm}$. Puouk organic ditambahkan dengancara dicampur dengan tanah galian. Kemudian ambil bibit dari tempat persemaian ke tempat penampungan bobit sementara. Selanjutnya lakukan penanaman bibit. Masukkan bibit sengon dengan hati-hati kedalam lubang tanam yang telah di buat, dan ditimbun dengan tanah yang sudah diberi pupuk organik. Pemeliharaan yang dilakukan meliputi : Penyulaman, Jika ada tanaman sengon yang mati malka lakukan pergantian tanaman tersebut dengan tanaman yang baru. Penyiangan, perlu dilakukan penyiangan terhadap gulma atau tanaman pengganggu lainnya yang ada di sekitar tanaman. Pendangiran, perlu dilakukan pendangiran tau penggemburan tanah agar memperbaiki stuktur tanah di sekitar tanaman.

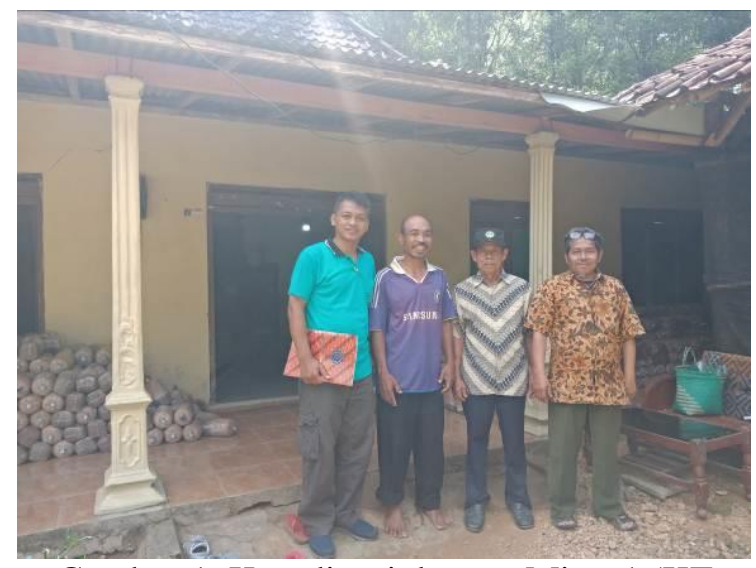

Gambar 1. Koordinasi dengan Mitra 1 (KT Ngudi Mulyo)

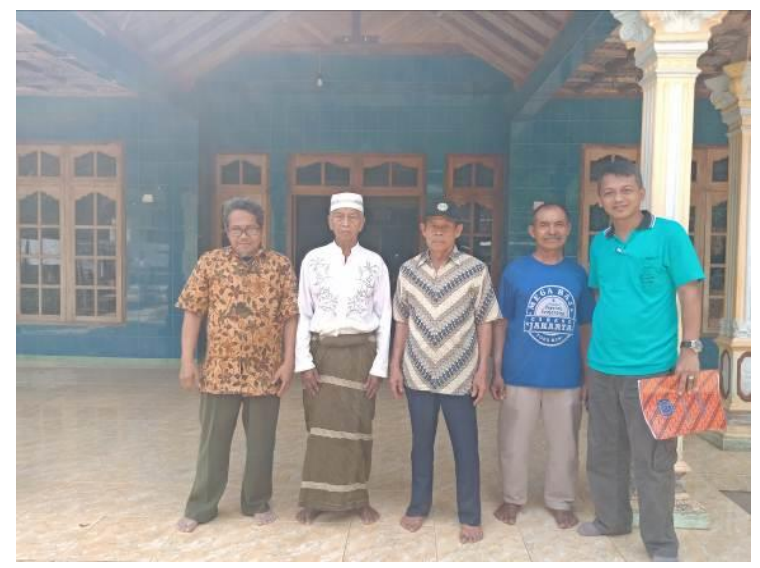

Gambar 2. Koordinasi dengan Mitra 2 (KT Ngudi Tani 1) 


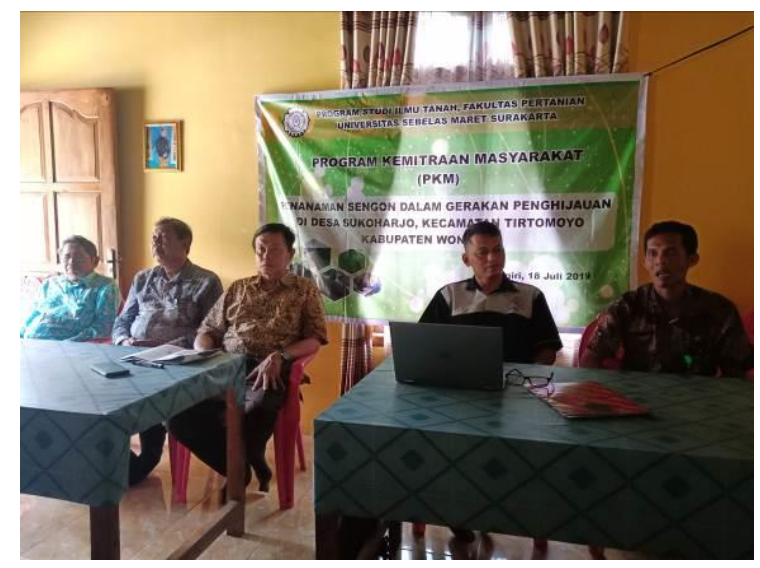

A

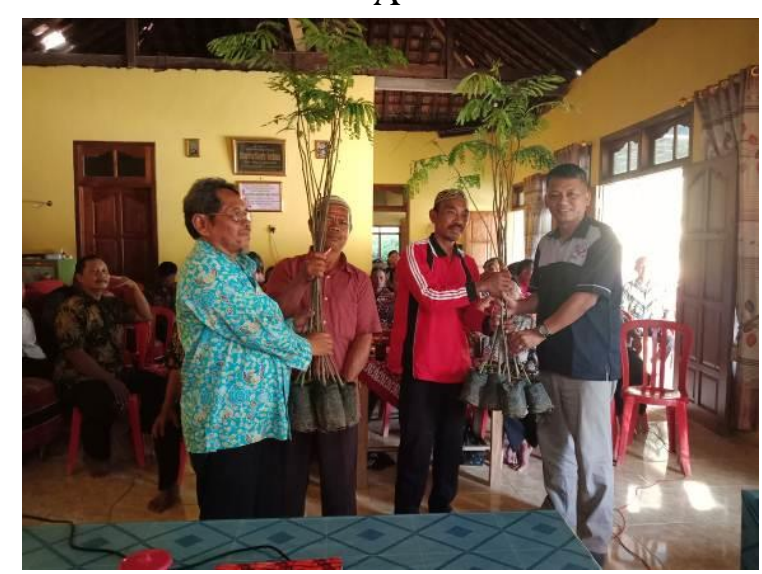

$\mathrm{C}$

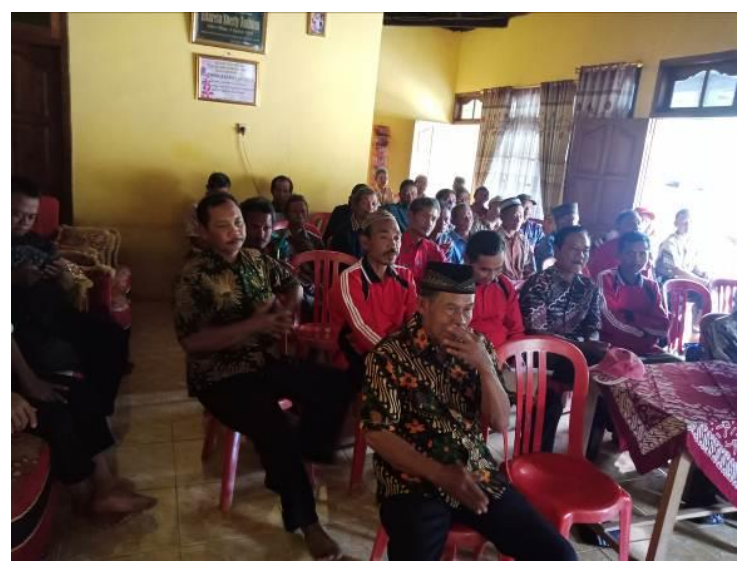

B

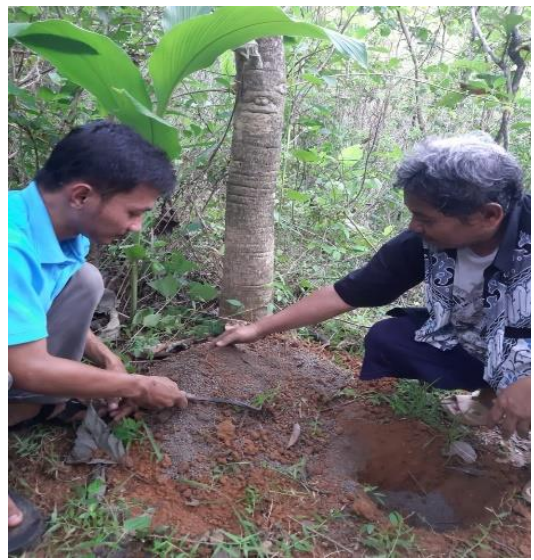

$\mathrm{D}$

Gambar 3. (A) Sosialisasi penghijauan dengan tanaman sengon; (B) Peserta sosialisasi; (C) Pemberian bibit sengon kepada Mitra; (D) Penyiapan penanaman, aplikasi pupuk organic

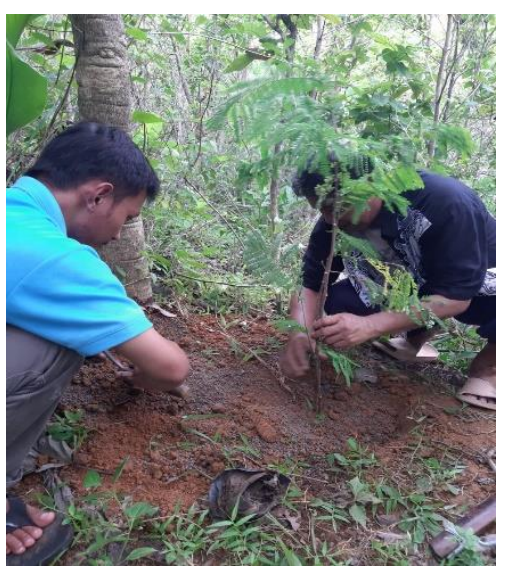

a

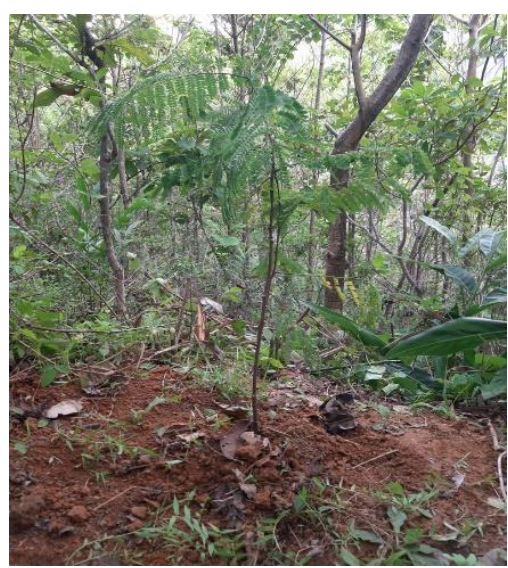

b

Gambar 4. (a) Penanaman bibit sengon; (b) Bibit sengon yang sudah ditanam

\section{UCAPAN TERIMA KASIH}

Ucapan terimakasih kami tujukan kepada Universitas Sebelas Maret (UNS) yang telah mendanai kegiatan ini melalui Anggaran PNBP tahun 2019.

\section{KESIMPULAN}

Dari kegiatan pengabdian yang telah dilakukan, maka dapat diambil beberapa kesimpulan: 
1. Kegiatan pengabdian telah terlaksana sesuai dengan rencana yang telah disusun bersama dengan Kelompok Tani Mitra.

2. Penghijauan dengan tanaman sengon sangat diharapkan oleh warga, terutama untuk mengurangi erosi tanah.

3. Petani yang tergabung dalam Kelompok Tani Mitra sangat antusias dalam kegiatan yang dilakukan (sosialisasi dampai penanaman sengon).

4. Sosialisasi perlu dilakukan kepada masyarakat, sehingga secara mandiri bisa melakukan upaya konservasi dengan cara vegetative yang selaras dengan kondisi alam setempat.

\section{DAFTAR PUSTAKA}

Karyati, S. Sarminah, 2018. Teknologi Konservasi Tanah dan Air. Mulawarman University Press, Samarinda.

Rubiantoro, E.A., Haryanto, R., 2013. Bentuk Keterlibatan Masyarakat dalam Upaya Penghijauan pada Kawasan Hunian Padat di Kelurahan Serengan - Kota Surakarta. J. Pembang. Wil. Dan Kota 9, 416-428.
Subagyono, K., Marwanto, S., Kurnia, U., 2003. Teknik Konservasi Tanah secara Vegatetif. Balai Penelitian Tanah. Pusat Penelitian dan Pengembangan Tanah dan Agroklimat. Departemen Pertanian.

Sukasah, M.G., A.Rahmadiningrat, H. A. Ningrum, 2018. Konservasi Tanah dan Air Di Lahan Pertanian Bandung Timur [WWW Document]. UIN Sunan Gunung Djati Bdg. URL https://scholar.google.co.id/scholar?safeh ttp://digilib.uinsgd.ac.id/9404/1/paper\%2 0kta\%20pdf\%20Moch.\%20Gumilar.pdf= strict\&biw=1366\&bih=576\&um=1\&ie= UTF-

8\&lr\&q=related:dlTMg6wdIz809M:scho lar.google.com/ (accessed 1.24.20).

Sutrisno, N., N. Heryani, 2013. Teknologi Konservasi Tanah dan Air untuk Mencegah Degradasi Lahan Pertanian Berlereng. J. Litbang Pertan. 32, 122-130. 